\title{
TOPORY KAMIENNE I SIEKIERA KRZEMIENNA Z OKOLIC GIECZA (POW. ŚREDZKI WIELKOPOLSKI, WOJ. WIELKOPOLSKIE) W KONTEKŚCIE OSADNICTWA NEOLITYCZNEGO
}

\author{
NEOLITHIC STONE AXES AND A FLINT AXE FROM \\ THE VICINITY OF GIECZ (ŚRODA WIELKOPOLSKA COUNTY, \\ WIELKOPOLSKIE PROVINCE) \\ IN THE CONTEXT OF NEOLITHIC SETTLEMENT
}

\author{
Elżbieta Indycka \\ Muzeum Pierwszych Piastów na Lednicy, Oddział Rezerwat Archeologiczny w Gieczu \\ Grodziszczko, 63-012 Dominowo \\ ela.indycka@gmail.com
}

\begin{abstract}
The aim of the article is to discuss two previously unpublished Neolithic stone axes and a flint one, found in the vicinity of the Archaeological Reserve in Giecz. The artefacts have been discussed in the context of the Neolithic settlement from the area of their discovery.
\end{abstract}

KEY WORDS: stone axe, flint axe, Neolithic.

W zbiorach Muzeum w Gieczu (Oddział Muzeum Pierwszych Piastów na Lednicy) przechowywane są materiały krzemienne odkryte podczas prac wykopaliskowych i powierzchniowych na stanowiskach (z okresu wczesnego średniowiecza) w okolicy grodziska w Gieczu. Materiały te były przedmiotem pracy licencjackiej (Banach 2014) ${ }^{1}$. Jednak znalezienie ich wyłącznie na złożu wtórnym i zniszczenia spowodowane procesami podepozycyjnymi nie pozwoliły na określenie ich przynależności kulturowej - mimo szczegółowej analizy technologicznej; dla większośćci artefaktów ustalono szerokie ramy chronologiczne od epoki kamienia do epoki brązu.

Ponadto w zbiorach Muzeum znajdują są dwa topory neolityczne, które z kolei są znaleziskami przypadkowymi, przekazanymi do Muzeum przez znalazców.

Celem niniejszego artykułu jest omówienie kamiennych toporów i siekiery krzemiennej w kontekście osadnictwa neolitycznego w sąsiedztwie miejsc ich znalezienia.

\footnotetext{
${ }^{1}$ Dziękuję Panu Filipowi Banachowi za udostępnienie pracy licencjackiej.
} 


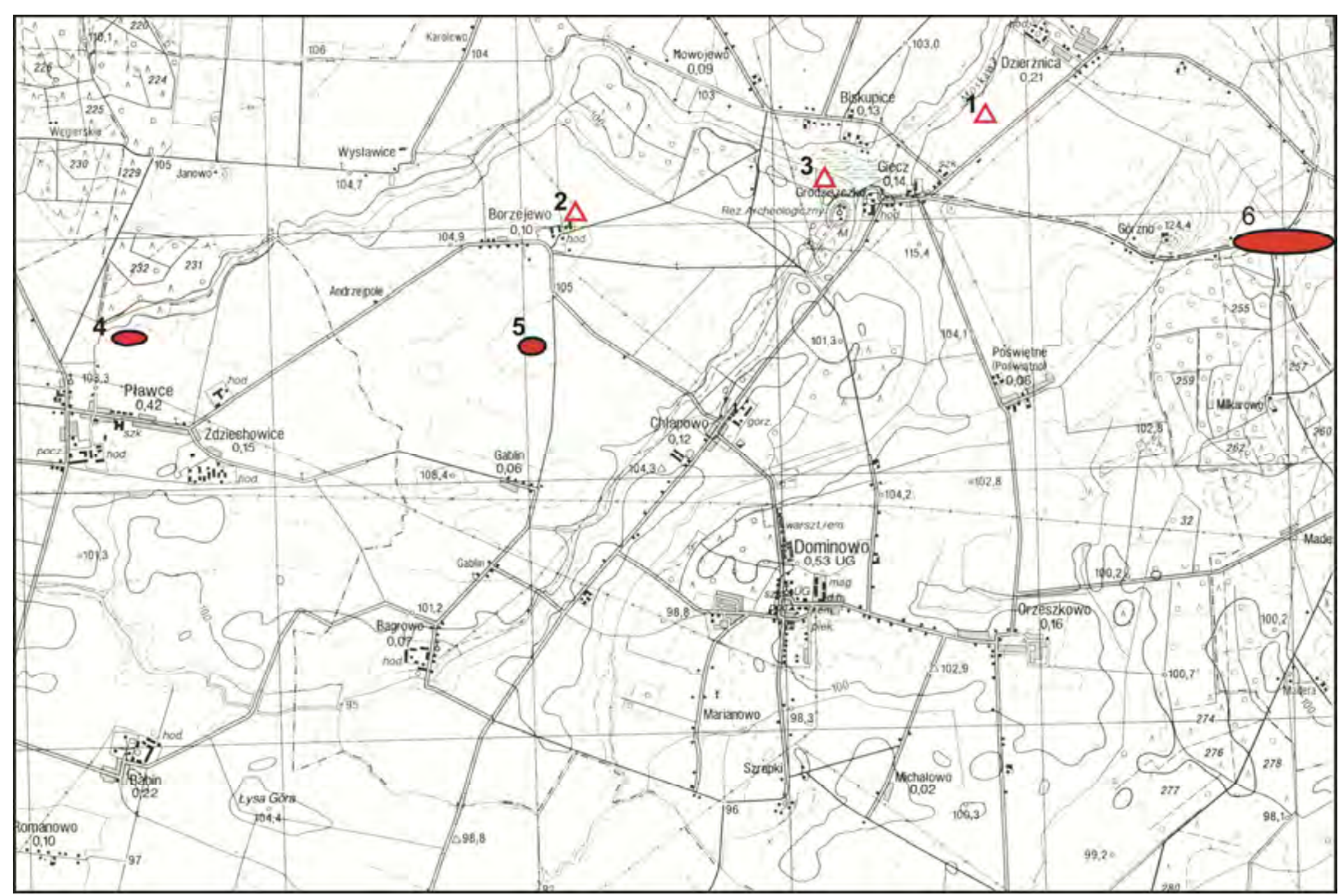

Ryc. 1. 1-3 - miejsca znalezienia toporów i siekiery; 4-6 - stanowiska z okresu neolitu, na których przeprowadzono badania wykopaliskowe (oprac. Tomasz Kasprowicz)

Fig. 1. 1-3 - Location of findings of the stone axes and a flint axe; 4-6 - Neolithic sites which have been excavated (by Tomasz Kasprowicz)

Jeden z toporów został znaleziony w okolicach Borzejewa (ok. 2,5 km na zachód od Giecza), bez informacji o dokładnej lokalizacji miejsca odkrycia. Drugi natomiast znaleziono na polu pomiędzy Gieczem a Dzierżnicą (ok. 0,5 km na północ od Giecza), na wschodnim stoku doliny Moskawy (ryc. 1).

Ten skromny zbiór jest niejednolity pod względem techniczno-typologicznym i chronologiczno-kulturowym. Przynależność kulturową i chronologiczną toporów określono na podstawie cech morfologiczno-typologicznych, wykorzystując powszechnie przyjęte schematy klasyfikacji tego typu wytworów użytkowanych w neolicie (Czerniak 1980; Machnik 1966).

Topór znaleziony w okolicach Dzierżnicy (ryc. 2) ma 11,5 cm długości, 4,1 cm wysokość i 4,4 cm szerokości; szerokość ostrza wynosi $2,9 \mathrm{~cm}$, a średnica otworu 1,7-1,9 cm. Środek otworu znajduje się niemal dokładnie na 2/3 długości narzędzia, jednak nie jest umieszczony w połowie szerokości, lecz jest nieco przesunięty w bok od linii osi długiej, co w powiązaniu z tym, że jedna ścianka boczna jest niemal płaska, 


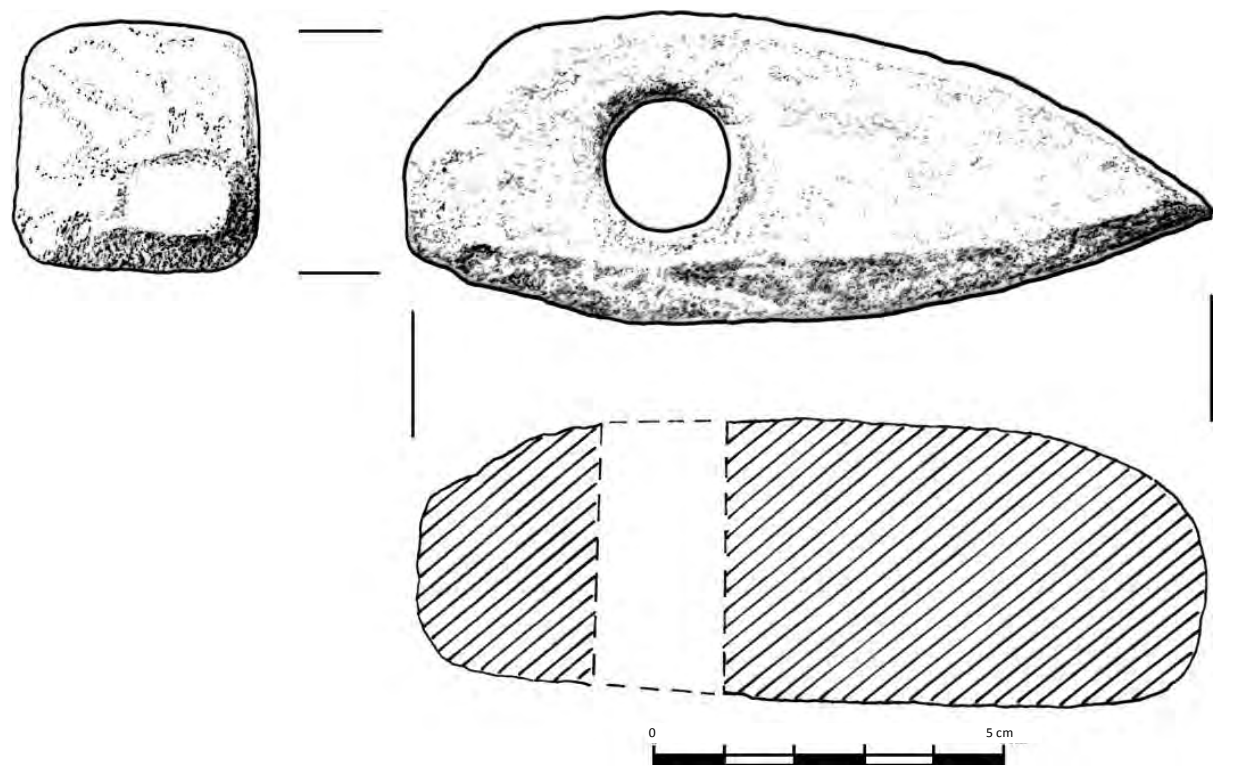

Ryc. 2. Topór kamienny znaleziony w okolicach Dzierżnicy (gm. Dominowo, pow. średzki, woj. wielkopolskie) (rys. Dorota Jagłowska)

Fig. 2. Stone axe found in the vicinity of Dzierżnica (com. Dominowo, Środa Wielkopolska county) (by Dorota Jagłowska)

druga zaś lekko wypukła, sprawia, że toporek jest niesymetryczny. Otwór ma kształt walcowaty, równoległy do ostrza, umieszczony bliżej obucha. Krawędzie boczne jednej ze ścianek są wyraźnie łukowate, nieznacznie ścięte w części przy ostrzu. Druga ścianka ma łukowaty kształt w części przy ostrzu i obuchu, natomiast w części środkowej jest niemal prosta. Część z obuchem jest niesymetryczna, co jest spowodowane zniszczeniem tej części (niemal połowy) narzędzia. Powierzchnia obucha ma kształt owalny i jest lekko wypukła, a ostrze jest niesymetryczne.

Powierzchnia toporka nie jest wygładzona nawet przy ostrzu. Jedynie powierzchnia obucha jest gładka, jak również częściowo wnętrze otworu. Krawędzie przy otworach są lekko obtłuczone. Można sadzić, że obróbka okazu nie została sfinalizowana - dotyczy to zwłaszcza płaszczyzn bocznych i obucha.

Topór został wykonany z bazaltu; jednak na podstawie badań makroskopowych nie sposób rozstrzygnąć, czy do jego wyrobu użyto surowca pochodzenia eratycznego, czy też jest to bazalt proweniencji spoza Niżu Polskiego, np. zachodniosudeckiej lub wołyńskiej².

Omówione cechy morfologiczne topora z Dzierżnicy charakterystyczne są dla form toporów późnowstęgowych. Znaleziska tego typu toporów są stosunkowo licz-

\footnotetext{
${ }^{2}$ Dziękuję dr. Piotrowi Chachlikowskiemu za wykonanie analizy petrograficznej.
} 
ne na terenie Wielkopolski (Prinke i Skoczylas 1980, s. 70, tab. 7; tab. 6-10; Smoczyńska 1953, s. 1-73).

Topór znaleziony w okolicach Borzejewa (ryc. 3) ma 10,2 cm długości, 4,2 cm szerokości oraz 4,2 cm grubości. Walcowaty otwór ma trzonek o średnicy 1,5-1,7 $\mathrm{cm}$, jest wywiercony jednostronnie. Obuch jest zaokrąglony, spłaszczony. Ścianki boczne są łukowate, nieznacznie ścięte na krawędziach, a ostrze jest asymetryczne. Jego ogólne cechy morfologiczne pozwalają zaliczyć go pod względem typologicznym do typu III toporów kultury ceramiki sznurowej wg J. Machnika (1966, s. 42, tab. XXXII: 2, 4). Świadczą o tym jego proporcje: szerokość zbliżona do grubości, długość ponad dwa razy większa od szerokości, co nadaje okazowi smukłości. Część obuchowa jest zaokrąglona i nieco wydłużona, a otwór umieszczony bliżej ostrza. Łukowate niesymetryczne ostrze jest nieco węższe niż grubość topora. Okaz ten jest starannie wykonany, symetryczny, bardzo dokładnie wygładzony również wewnątrz otworu. Jedynie przy krawędziach otworu widoczne są ślady obtłukiwania, najpewniej związane z techniką wiercenia otworów. Do jego wykonania użyto gabra, surowca pochodzenia eratycznego, dostępnego na Niżu Polskim wśród eratyków fennoskandzkich.
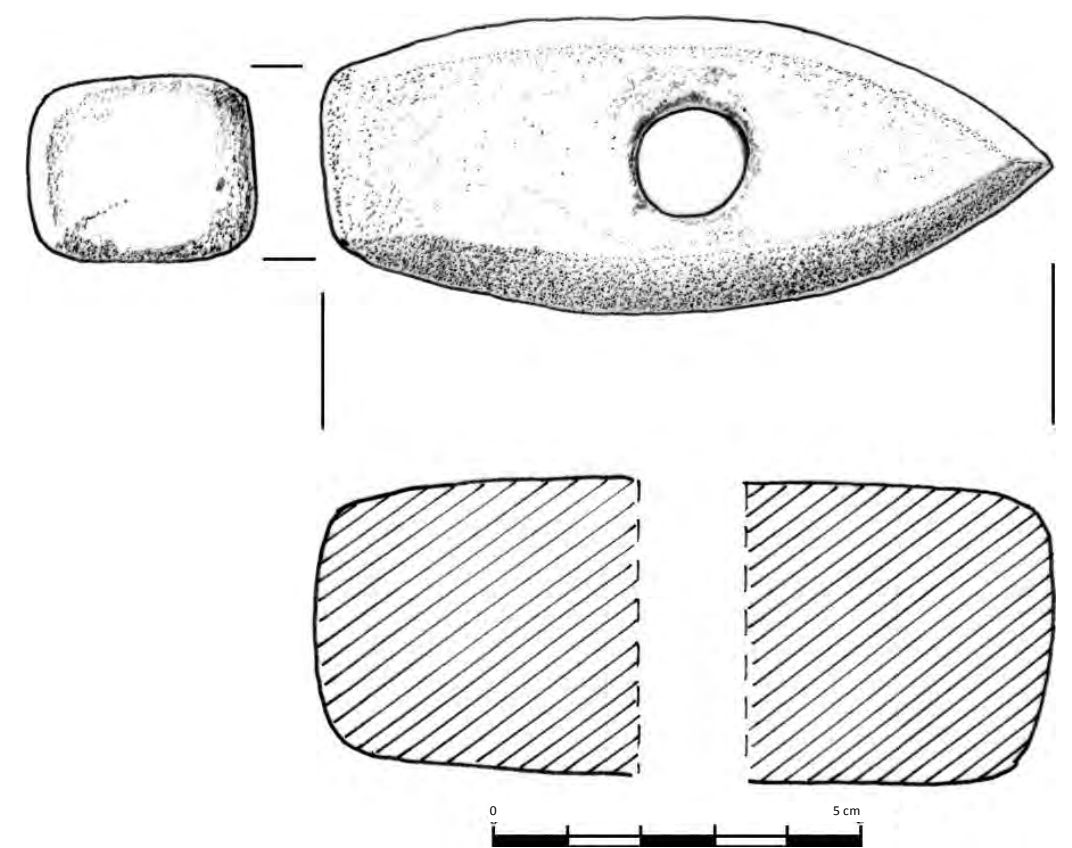

Ryc. 3. Topór kamienny z okolic Bożejewa (gm. Dominowo, pow. średzki, woj. wielkopolskie) (rys. Dorota Jagłowska)

Fig. 3. Stone axe found in the vicinity of Bożejewo (com. Dominowo, Środa Wielkopolska county) (by Dorota Jagłowska) 
Krzemienną siekierkę (ryc. 4) znaleziono na powierzchni stanowiska 4 w Gieczu. Na tym wczesnośredniowiecznym stanowisku prowadzone były szczegółowe badania powierzchniowe, a także wykopaliskowe, jednak dotąd (poza kilkunastoma krzemieniami) nie odkryto neolitycznych obiektów nieruchomych.

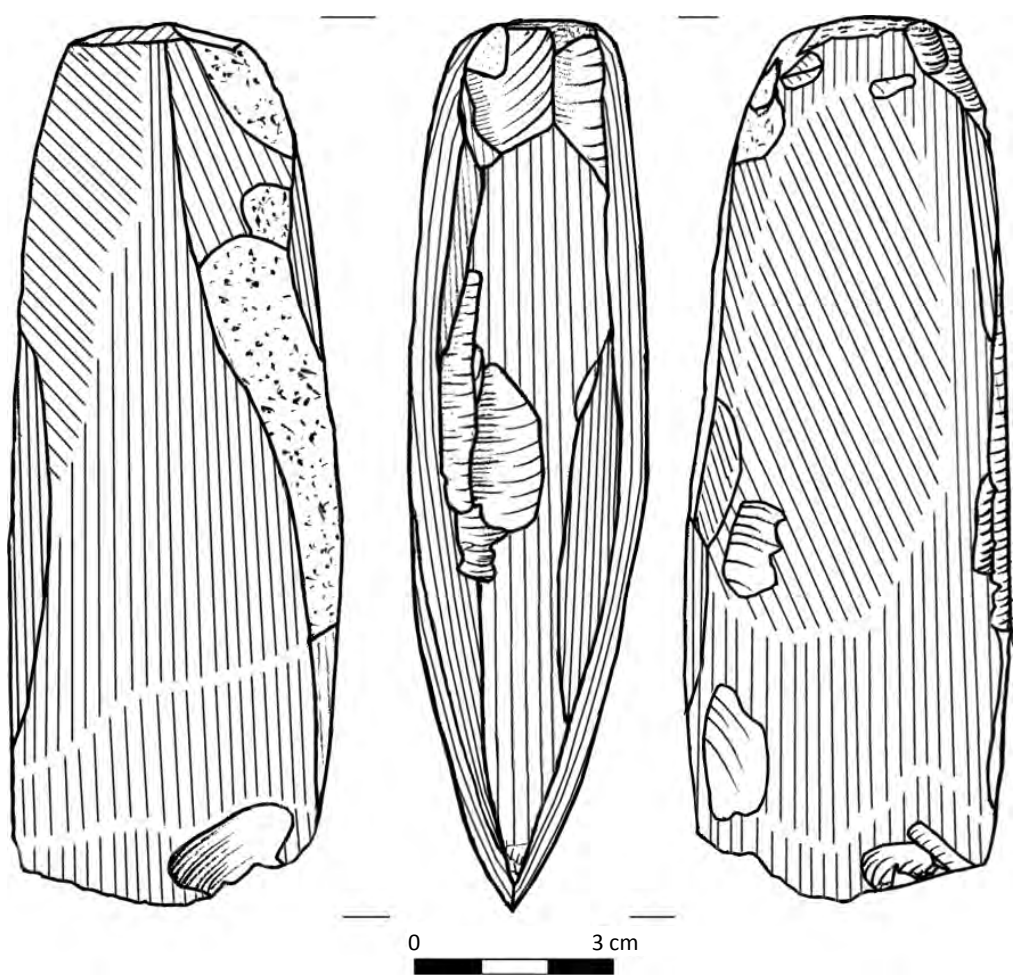

Ryc. 4. Siekiera krzemienna ze stanowiska 4 w Gieczu (gm. Dominowo, pow. średzki, woj. wielkopolskie) (rys. Hubert Lepionka)

Fig. 4. Flint axe from site 4 in Giecz (com. Dominowo, Środa Wielkopolska county) (by Hubert Lepionka)

Siekierka ma 13,1 cm długości, 4,8 cm szerokości i 3,45 cm grubości. Szerokość obucha wynosi $3 \mathrm{~cm}$ a grubość $2,6 \mathrm{~cm}$. Cechami charakterystycznymi siekierki są lekko wypukłe ścianki oraz łukowate krawędzie - i mimo że w zasadzie ma ona kształt trapezu, odróżnia się np. od siekier kultury amfor kulistych, których ścianki są bardziej płaskie, a krawędzie proste. Płaski obuch jest węższy od największej szerokości siekiery, węższy jest także od szerokości ostrza. W przekroju poprzecznym siekiera ma kształt prostokąta o łukowatych ściankach, natomiast w przekroju pionowym ma kształt soczewki, ściętej z jednej strony, czyli przy obuchu. Cechą szczególną siekierki jest jej staranne gładzenie na całej powierzchni. 
Na podstawie wymienionych cech można zauważyć podobieństwo gieckiej siekiery do siekier kultury pucharów lejkowatych, a zwłaszcza siekier z młodszych faz tej kultury, dla której wyróżniona została odmiana o wypukłych ściankach i łukowatych krawędziach (Wiślański 1979, s. 230, 232, ryc. 133:15, 16).

W trakcie badań AZP prowadzonych w obrębie arkuszy (53-31, 53-32 oraz 54-31 i 54-32) zarejestrowano łącznie 156 stanowisk neolitycznych, w tym też takich, których chronologia została określona ogólnie jako „epoka kamienia”, „schyłkowy neolit" itp. Na podstawie danych zebranych przez J. Wierzbickiego (2013, s. 41-47) liczba stanowisk na wymienionych arkuszach z podziałem chronologicznym i kulturowym jest następująca:

1) datowane ogólnie na okres neolitu - 14 stanowisk; są to tzw. ślady osadnicze o małej wartości poznawczej;

2) łącznie z kultur ceramiki wstęgowej rytej, ceramiki wstęgowej kłutej i lendzielskiej - 2 stanowiska, także o małej wartości poznawczej;

3) kultura pucharów lejkowatych - 84 stanowiska, a wśród nich trzy stanowiska badane wykopaliskowo (Pławce, Borzejewo i Dzierżnica), o dużej wartości poznawczej;

4) łącznie z kultury amfor kulistych i ceramiki sznurowej oraz datowanych na okresy schyłkowego neolitu i wczesnej epoki brązu - 13 stanowisk.

Pod względem podziału geomorfologicznego teren, na którym zlokalizowane są wymienione stanowiska, jest częścią Równiny Wrzesińskiej. Wpływ na ukształtowanie powierzchni miała działalność lądolodu i jego wód roztopowych zlodowacenia Wisły. Dominującym elementem morfologii rzeźby jest wysoczyzna morenowa płaska, urozmaicona przez liczne rynny polodowcowe o znacznej głębokości. Rynny te obecnie zajęte są przez rzeki - największą z nich jest Moskawa, prawy dopływ Warty.

Badania geologiczne ujawniły istnienie kopalnych jezior na tym terenie, co pozwoliło na odtworzenie dawnego, znacznie bardziej urozmaiconego niż dziś, układu hydrograficznego w okolicach Giecza. Kopalne jeziora (o nieokreślonym czasie ich zaniku) odkryto m.in. na wschód od Giecza, w okolicach stanowiska Dzierżnica 35, a także na północ od Borzejewa, którego dolina zajęta jest obecnie przez Zagajski Potok, zachodni dopływ Moskawy. Największy zbiornik wodny znajdował się na północ od Giecza (Kowalewski, Gałka 2007, s. 109; Pietsch 2010, s. 11-14, 26-27, 30-37).

Badania wykopaliskowe prowadzono jedynie na tych stanowiskach, które znajdowały się w pasie wyznaczonym pod budowę autostrady A2:

- Pławce, stanowisko 8, gm. Środa Wlkp. (Wierzbicki 2013);

- Borzejewo, stanowisko 22, gm. Dominowo, pow. średzki, woj. wielkopolskie (Wierzbicki 2001a);

- Chłapowo, stanowisko 2 i 21, gm. Dominowo, pow. średzki, woj. wielkopolskie;

- Dzierżnica, stanowisko 35, gm. Dominowo, pow. średzki, woj. wielkopolskie (Wierzbicki 2009, 2011b); 
- Dzierżnica 42, gm. Dominowo, pow. średzki, woj. wielkopolskie;

- Dzierżnica 44, gm. Dominowo, pow. Środa Wlkp.;

- Stępocin stanowisko 33/34, gm. Nekla, pow. Września (Woźniak 2007).

Na wszystkich tych stanowiskach o wielokulturowym charakterze zarejestrowano materiały ruchome i nieruchome z okresu neolitu, jednak dotąd nie opublikowano całości materiałów neolitycznych. Ze zbioru stanowisk neolitycznych szczegółowo przeanalizowane i opublikowane zostały jedynie materiały kultury pucharów lejkowatych, zarejestrowane na wszystkich wymienionych stanowiskach, oraz kultury ceramiki sznurowej ze stanowiska Dzierżnica 35. (Maszynopis z wynikami badań pozostałych stanowisk znajduje się w archiwum NID w Warszawie).

$\mathrm{Na}$ omawianym obszarze odnotowano obecność pojedynczych materiałów ruchomych wiązanych z kulturami cyklu naddunajskiego, które można zinterpretować jako ślady penetracji tego obszaru przez społeczności tych jednostek kulturowych.

Najliczniejsze źródła (nieruchome i ruchome) wiązane są z osadnictwem ludności kultury pucharów lejkowatych z Pławiec, Borzejewa i Dzierżnicy. Warto odnotować, że na ostatnim $\mathrm{z}$ wymienionych stanowisk zarejestrowano pozostałości niewielkiej i niezbyt intensywnie użytkowanej osady datowanej na fazę K IIA KPL. Uzyskane dane są dowodem na wczesne osadnictwo społeczeństw kultury pucharów lejkowatych w tej części Wielkopolski (Wierzbicki 2009, s. 32).

Na stanowisku Dzierżnica 35 odkryto nieliczne i rozproszone na badanym obszarze obiekty nieruchome kultury ceramiki sznurowej, świadczące o niezbyt intensywnym, prawdopodobnie dwufazowym osadnictwie społeczności tej kultury. Pierwszą fazę można datować na horyzont środkowoeuropejski, drugą na schyłek neolitu, początki epoki brązu (Wierzbicki 2011b, s. 39).

Nieliczne materiały z okresu schyłkowego neolitu z tego terenu rejestrowano również w obrębie pozostałych badanych wykopaliskowo stanowisk.

Uzyskane dotychczas dane archeologiczne pochodzące z badań powierzchniowych i prac wykopaliskowych wskazują, że na omawianym wycinku obszaru Wielkopolski zaznaczyła się obecność rozmaitych ugrupowań społeczności neolitycznych. Podobnie jak na większych połaciach regionu pozostałości osadnictwa neolitycznego mają charakter krótkotrwały i rozproszony. Na tym niewielkim analizowanym obszarze widoczna jest również intensywniejsza działalność ludności kultury pucharów lejkowatych.

Wnioski wynikające $\mathrm{z}$ analiz materiałów archeologicznych znajdują potwierdzenie w badaniach paleobotanicznych. Materiał do badań palinologicznych pobrany został z osadów wypełniających misę bezimiennego jeziora, które w przeszłości było największym zbiornikiem wodnym na omawianym obszarze. Można nadmienić, że jezioro to, przez które przepływa największa na tym terenie rzeka Moskawa, znajduje się $\mathrm{w}$ centrum omawianego obszaru, mniej więcej $\mathrm{w}$ połowie drogi pomiędzy stanowiskami w Pławcach i Borzejewie a stanowiskami w Stępocinie i Dzierżnicy. 
Analiza diagramów pyłkowych wskazuje, że działalność gospodarcza grup ludności z przełomu mezolitu i neolitu była niezbyt intensywna i nie spowodowała trwałych zmian w środowisku. Interesujące jest występowanie pyłu węglowego w osadach datowanych na ten okres. Jego obecność świadczy o wypalaniu niewielkich połaci lasów, co skutkowało szybką i obfitą regenerację runa leśnego.

Profil pyłkowy z okresu neolitu nie wskazuje, aby w tym czasie zmienił się wyraźnie stosunek powierzchni leśnych i zbiorowisk otwartych; jednak odnotowano przerzedzenie lasów. Dla tego okresu charakterystyczne są liczne węgielki drzewne, co świadczy o intensywniejszym niż w poprzednim okresie wypalaniu części lasów. Dodatkowo pyłki szczawiu i babki lancetowatej wskazują na możliwość wykorzystywania prześwietlonych lasów jako miejsc wypasu zwierząt. Stwierdzono występowanie pyłków roślin uprawnych: Triticum i Cerealia.

Okres schyłkowego neolitu zaznaczył się w diagramach pyłkowych wzrostem obecności pyłków roślin łąkowych, szczawiu i babki lancetowatej, co świadczy o większym niż w poprzednim okresie użytkowaniu zbiorowisk otwartych i przerzedzonych lasów. Interesujące jest też to, że w badanych próbach nie jest odnotowano obecności roślin uprawnych, jak również węgielków drzewnych czy pyłu węglowego. Fakt ten interpretowany jest jako ilustracja gospodarki społeczności kultury amfor kulistych - z przewagą hodowli i mniejszym znaczeniem upraw (Milecka 1998, s. 74-78).

Podsumowując wyniki analiz archeologicznych i paleobotanicznych, wypada stwierdzić, że na omawianym wycinku obszaru Wielkopolski, z którego pochodzą analizowane topory i siekiera, aktywność społeczności neolitycznych zaznaczyła się w niewielkim zakresie. Stwierdzono jedynie, iż nieliczne grupy ludzkie zakładały tam krótkotrwałe osady.

W tym kontekście znaleziska toporów i siekiery można traktować jako dowody ruchliwości jednostek bądź grup ludzkich penetrujących ten teren. Pytanie, czy atrakcyjne tereny wokół gieckiego jeziora były również atrakcyjne dla neolitycznych wędrowców, na razie pozostaje bez odpowiedzi.

Można zatem przypuszczać, że omówione znaleziska „przebyły” długą drogę w czasie i przestrzeni, by w końcu znaleźć się w Magazynie Zabytków Wydzielonych w Muzeum w Gieczu.

\section{BIBLIOGRAFIA}

Banach F.

2014 Materiały krzemienne z wybranych grodzisk wczesnośredniowiecznych. [Praca licencjacka w Archiwum Muzeum w Gieczu].

Czerniak L.

1980 Rozwój społeczeństw kultury późnej ceramiki wstęgowej na Kujawach. Poznań: Wydawnictwo Naukowe Uniwersytetu im. Adama Mickiewicza. 
Gałka M., Kowalewski G.

2007 Geneza i rozmieszczenie zbiorników wodno-torfowiskowych. W: A. Grygorowicz, K. Milecka, K. Tobolski (red.), Architektoniczno-przestrzenne i przyrodnicze podstawy rekonstrukcji wczesnośredniowiecznych założeń obronnych Giecza (s. 87-103). Poznań: Instytut Architektury i Planowania Przestrzennego Wydziału Architektury Politechniki Poznańskiej.

Machnik J.

1966 Studia nad kultura ceramiki sznurowej w Małopolsce. Wrocław-Warszawa-Kraków, Zakład Narodowy im. Ossolińskich.

Milecka K.

1998 Historia działalności człowieka w okolicach Giecza i Wagowa w świetle analizy pyłkowej. W: K. Tobolski (red.), Biblioteka Studiów Lednickich (t. III, s. 43-95). Poznań.

Pietsch A.

2010 Budowa geologiczna okolic Giecza ze szczególnym uwzględnieniem surowców skalnych. [Praca magisterska w Bibliotece Muzeum w Gieczu].

Prinke A., Skoczylas J.

1980 Neolityczne surowce kamienne w Polsce środkowo-zachodniej. Warszawa-Poznań: Państwowe Wydawnictwo Naukowe.

Smoczyńska $Ł$.

1953 Kultura ceramiki wstęgowej w Wielkopolsce. Fontes Praehistorici, 3, s. 1-84.

Sobucki A.

2003 Archeologiczne badania ratownicze na wielokulturowym stanowisku $35 \mathrm{w}$ Dzierznicy, gm. Dominowo, woj. wielkopolskie, przeprowadzone w roku 2002. Wielkopolskie Sprawozdania Archeologiczne, 6, s. 286-292.

Wierzbicki J.

2009 Dzierżnica, stanowisko 35, gm. Dominowo, pow. Środa Wielkopolska - trzecie stanowisko kultury pucharów lejkowatych z fazy wczesnowióreckiej w Wielkopolsce. Wielkopolskie Sprawozdania Archeologiczne, 10, s. 11-37.

Wierzbicki J.

2011a Osadnictwo ludności kultury pucharów lejkowatych na stan. 22 w Bożejewie, gm. Dominowo, pow. Środa Wlkp. Wielkopolskie Sprawozdania Archeologiczne, 12, s. 11-22.

Wierzbicki J.

2011b Osadnictwo społeczności kultury ceramiki sznurowej na stan. 35 w Dzierznicy, gm. Dominowo, pow. Środa Wielkopolska. Wielkopolskie Sprawozdania Archeologiczne, 12, s. 23-41.

Wierzbicki J.

2013 Wielka kolonizacja. Społeczności kultury pucharów lejkowatych w dorzeczu środkowej Warty: koniec $V$-pot. III tys. BC. Biblioteka Wielkopolskich Sprawozdań Archeologicznych, t. VI. Poznań: Stowarzyszenie Naukowe Archeologów Polskich, Oddział w Poznaniu.

Wiślański T.

1979 Kształtowanie się miejscowych kultur rolniczo-hodowlanych. Plemiona kultury pucharów lejkowatych. W: W. Hensel, T. Wiślański (red.), Prahistoria ziem polskich (t. II, s. 165-260). Wrocław-Warszawa-Kraków-Gdańsk: Zakład Narodowy im. Ossolińskich.

Woźniak Z.

2007 Archeologiczne badania ratownicze na wielokulturowym stanowisku 33/34 (A2-288) w Stępocinie, gm. Nekla, pow. Września, woj. wielkopolskie. Komunikat z badań. Wielkopolskie Sprawozdania Archeologiczne, 8, s. 175-183. 


\section{NEOLITHIC STONE AXES AND A FLINT AXE FROM THE VICINITY OF GIECZ (ŚRODA WIELKOPOLSKA COUNTY, WIELKOPOLSKIE PROVINCE) IN THE CONTEXT OF NEOLITHIC SETTLEMENT}

\section{Su m mary}

The article addresses two neolithic stone axes and a flint axe, found accidentally, now in the collection of the Museum in Archaeological Reserve in Giecz.

On the basis of morphological features one of the axes - from Dzierżnica, could be dated to the early Neolithic (Linear cultures), provided, however, that stone implements of this culture are often found far beyond its settlement (Wierzbicki 2013, p. 158). In contrast, morphological features of the axe found in the vicinity of Bożejewo correspond to those of type III, of the Corded Ware culture in Małopolska (Machnik 1966, p. 42).

The flint axe was found at early medieval site 4, however, it seems to belong to the type of axes known from the Funnel Beaker culture, and especially its later phases, with a variant distinguished - with convex sides and arched edges (Wiślanski 1979, pp. 230, 232, Figs. 133: 15, 16).

The finds have been presented in the context of the neolithic settlement from the area of discoveries. Therefore, archaeological evidence has been discussed from Polish Archaeological Record surveys (sheets 54-31, 54-32, 55-31 and 55-32), and the excavations carried out in advance of the A2 motorway, together with the results of pollen analysis of sediments from Giecz lake.

Thus, it could be assumed that the remains of a neolithic settlement in the area are scattered and sparse, giving evidence of short-term stay of few communities in the area, and that they might have resulted more from its penetration than the long-term occupation. There is no reason to suggest any relationship between these finds and the remnants of settlement of cultures to which they have been assigned, let alone the fact that their presence where they were found might have been accidental. 